\title{
Cryoprecipitate and the Plastic Blood-bag System : Provision of Adequate Replacement Therapy for Routine Treatment of Haemophilia
}

\author{
ENID BENNETT,* M.B., B.S.; KATHARINE M. DORMANDY,* M.B., M.R.C.P., M.C.PATH. \\ WENDY G. L. CHURCHILL,* A.A.I.M.I.T. ; A. R. COWARD,* A.I.M.L.T. ; M. SMITH, $\dagger$ B.SC. \\ T. E. CLEGHORN, $\dagger$ M D., B.SC.
}

rrit. med. F., 1967, 2, 88-91

In a survey of 210 young haemophiliacs living in South-east England it was recently shown that, by modern standards, under $20 \%$ received adequate treatment (Dormandy et al., 1967). The long-term management of the remainder fell short of what can and should be achieved even with the limited resources at present available to the hospital service. It was found, for example, that the potency of the frozen plasma issued at the time of the survey by the North London Blood Transfusion Centre was often too low to be of any clinical benefit. This led to a comparative trial of plasma processed at the haemophilia centre of the Royal Free Hospital and at the transfusion centre. At the same time a number of technical procedures were explored, particular attention being paid to the selection of those which could be widely adopted. After the report of Pool and Shannon (1965) cryoprecipitate rich in factor VIII was prepared ; 537 bags of this have been used in the trial since April 1966.

In the course of the trial 239 infusions were given for 121 episodes of bleeding in patients with haemophilia. A further 23 infusions were given to patients with von Willebrand's disease. The results of the latter have been reported elsewhere (Bennett and Dormandy, 1966). A total of 1,304 pints (in 500 ml. units) of blood were used. The 914 pints which were collected by the plastic-bag method and processed at the haemophilia centre yielded 2,019 blood components, which were used separately. Supernatant plasma left after the separation of cryoprecipitate was given to three patients with Christmas disease (factor IX deficiency) and to one patient with plasma thromboplastin antecedent (factor XI) deficiency. Specific assays for factor IX and factor XI activity were carried out on these preparations.

\section{Plasma Preparations}

Donors were bled either at the hospital or at regular bloodtransfusion sessions. Of the hospital donors, 70 underwent single plasmapheresis-that is, the separated red cells from the pint $(500 \mathrm{ml}$.) of blood donated were immediately returned to the donor (Kliman and Schwab, 1961). By means of this procedure donors could be bled at intervals of one to two weeks.

Cryoprecipitate.-Donors were bled into Fenwal JD-2 double plastic bags, consisting of a primary blood pack connected to a satellite bag. $500 \mathrm{ml}$. of blood was collected in not more than 10 minutes. The blood was spun within two and a half hours of taking (often immediately) at $4,600 \mathrm{~g}$ for 20 minutes at $4^{\circ} \mathrm{C}$. and the plasma separated. The satellite bag containing the plasma, which was not severed from the primary blood pack, was frozen in a $\mathrm{CO}_{2}$-ice-alcohol mixture. At first the cryoprecipitate was separated by slowly thawing the frozen plasma at $4^{\circ}$ C. for 24 hours, as recommended by Pool and Shannon

\footnotetext{
- Department of Haematology, Royal Free Hospital, North-western Branch, London N.W.3.

† North London Blood Transfusion Centre, Edgware, Middlesex.
}

(1965). More recently we have adopted part of the modified rapid method suggested by Brown et al. (1967), in which the frozen plasma is thawed at $8^{\circ} \mathrm{C}$. Other modifications suggested by these authors were not adopted, because we did not wish to open the closed system. At $8^{\circ} \mathrm{C}$. the frozen plasma takes only about two hours to thaw. After the cryoprecipitate had separated out, the bags were re-centrifuged for 20 minutes at $4^{\circ} \mathrm{C}$., and the supernatant plasma was run back into the primary blood pack. Alternatively, the supernatant plasma was collected into a third bag, and the packed red cells in the primary blood pack were issued as such. (A triple-bag system allows this transfer to be carried out without opening the closed system.) In either case 10-15 ml. of plasma was left with the cryoprecipitate in the satellite bag, which was stored at $-30^{\circ} \mathrm{C}$. On use the thawed cryoprecipitate from up to five satellite bags could be collected into a single $50-\mathrm{ml}$. syringe for injection. Washing out the series of satellite bags with $10 \mathrm{ml}$. of saline permitted the collection of the residual cryoprecipitate (equivalent to the factor VIII activity of up to one extra bag of cryoprecipitate).

Supernatant Plasma.-When this was not used for the reconstitution of the red-cell mass, the supernatant plasma separated from the cryoprecipitate was used in the treatment of coagulation defects in patients with a deficiency of either factor IX or factor XI.

Fresh-frozen Plasma in Plastic Bags.-The first stages in the preparation of fresh-frozen plasma were as above, with the exception that the plasma in the satellite bag was severed from the primary blood pack. It was frozen as before and stored at $-30^{\circ} \mathrm{C}$.

"Fresh Frozen Plasma."-Because of transport difficulties the processing of the preparation labelled "Fresh Frozen Plasma" by the transfusion centre did not begin until 10 to 18 hours after the donors had been bled. The blood was collected into non-siliconed glass bottles. The final preparations were 300400-ml. aliquots from pooled plasma derived from eight pints (4.5 litres) of blood. This product is referred to as frozen plasma in this report.

\section{Methods}

Factor VIII Assay.-Factor VIII was assayed by the onestage method of Hardisty and Macpherson (1962) during the first six months of the trial and after that by the two-stage method as given by Biggs and Macfarlane (1962). Assays, which were all done in the hospital laboratory, were carried out as follows: (1) on the plasma at the time of donation $\neq$; (2) on the plasma or cryoprecipitate at the time of thawing for therapeutic use; (3) on the supernatant plasma ; (4) on the patient's plasma, preinfusion; and (5) on the patient's plasma 10 minutes postinfusion. The $100 \%$ standard for the one-stage assay was obtained by using plasma from one of two donors whose factor VIII level was found to be $100 \%$

$¥$ On blood processed at the hospital only. 
when assayed against porcine standard by the two-stage method. The $100 \%$ standard for the two-stage assay was the porcine factor VIII standard supplied by Diagnostic Reagents, Thame, Oxon, England.

Dose Assessment and Administration.-Immediately before infusion the cryoprecipitate or fresh-frozen plasma was thawed at $37^{\circ} \mathrm{C}$. The dose required by individual patients was calculated on the basis of one bag of cryoprecipitate being equivalent in terms of factor VIII activity to $150 \mathrm{ml}$. of normal fresh plasma (Simson et al., 1966). The dose of whole plasma was assessed on the basis of $15 \mathrm{ml} . / \mathrm{kg}$. body weight.

Calculation of In-vitro Recovery.-One unit of factor VIII is defined as the activity of $1 \mathrm{ml}$. of plasma containing, on assay, $100 \%$ factor VIII. Recovery of factor VIII was calculated as follows :

Units of factor VIII activity $=$ Factor VIII (\%) $\times$ vol. plasma (ml.) of original plasma (Up) $=\frac{100}{100}$

Units of factor VIII activity Factor VIII (\%) $\times$ vol. cryo. (ml.) of cryoprecipitate (Uc)

100

Recovery in units

$$
=\frac{U c}{U p} \times 100
$$

The three parts of the equation may be combined:

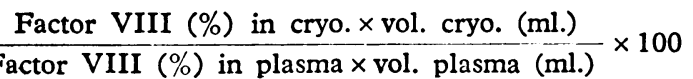

In assessing the percentage recovery in vitro the factor VIII lost in the supernatant plasma was included in the total losses incurred during the preparation of cryoprecipitate, and not subtracted from the factor VIII content of the original plasma to give a separate "starting activity" as reported by Brown et al. (1967).

Calculation of In-vivo Recovery.-In assessing the percentage recovery of factor VIII in a patient we have used the criteria of Biggs and Macfarlane (1966), whereby the dose in units $/ \mathrm{kg}$. is multiplied by 2.0 in the case of whole plasma infusions and by 2.4 for small-volume infusions such as those of cryoprecipitate. Full details are given by these authors for the rationale of this calculation. In this calculation we have used the following:

$$
\begin{aligned}
& \text { Dose in units }=\frac{\text { Vol. infused }(\mathrm{ml} .) \times \text { factor VIII (\%) }}{100} \frac{\text { Dose in units }}{\text { Weight in kg. }} \\
& \text { Dose in units } / \mathrm{kg} . \text { body weight }=\text {. }
\end{aligned}
$$

Expected rise of factor VIII (\%)=Dose in units $/ \mathrm{kg} . \times 2.4$ (or 2.0 ) Actual rise of factor VIII $(\%)=$ Postinfusion - Preinfusion levels $\%$ Recovery $=\frac{\text { Actual rise factor VIII }(\%)}{\text { Expected rise factor VIII }(\%)} \times 100$

Statistics.-Statistical analysis of results was carried out by one of us (E. B.). Student's $t$ test was applied, to look for a significant difference between the means of unpaired samples $(\mathbf{P}<0.05)$.

\section{Findings}

Table I shows the number of pints of blood processed at the hospital and the components prepared. The platelet concentrates and packed or reconstituted red cells were used for

\begin{tabular}{|c|c|c|c|c|c|c|c|}
\hline $\begin{array}{c}\text { Blood } \\
\text { Processed } \\
\text { in pints } \\
(500 \mathrm{ml} \text {. units })\end{array}$ & $\begin{array}{c}\text { Total } \\
\text { Com- } \\
\text { ponents }\end{array}$ & $\begin{array}{l}\text { Red } \\
\text { Cells }\end{array}$ & $\begin{array}{l}\text { Fresh- } \\
\text { frozen } \\
\text { Plasma } \\
\text { (Bags) }\end{array}$ & $\begin{array}{l}\text { Cryopre- } \\
\text { cipitate }\end{array}$ & $\begin{array}{l}\text { Super- } \\
\text { natant } \\
\text { Plasma }\end{array}$ & $\begin{array}{l}\text { Platelet } \\
\text { Con- } \\
\text { centrate }\end{array}$ & $\begin{array}{c}\text { Fresh } \\
\text { Plasma }\end{array}$ \\
\hline 914 & 2,019 & 914 & 598 & 316 & 124 & 30 & 37 \\
\hline
\end{tabular}
patients other than those with coagulation disorders, and are not, therefore, included further.

Factor VIII Activity in Cryoprecipitate.-Analysis of the results on cryoprecipitate was carried out on data from material Figures from the transfusion centre are omitted
tracing components which went to other hospitals. processed at the hospital. In-vitro figures were not available on cryoprecipitate made at the transfusion centre. Table II shows the results obtained by the slow and rapid methods of thawing. There was a greater loss of factor VIII into the supernatant plasma with the rapid thaw ; but by chance this was offset by the higher content of factor VIII in the original plasma. There was no significant difference between the total percentage recovery obtained by the two methods $(P>0.4)$. Separate assays of 32 samples of saline washings from the bags showed that the factor VIII content was approximately 800$900 \%$. It was estimated that inclusion of the washings in the dose given increases the recovery from the patients by approximately $10 \%$.

TABLE II.-Comparison Between the Slow and Rapid Methods of Thawing Fresh-frozen Plasma for the Preparation of CryoprecipitateGroups $A$ and $O$ Rhesus-positive Blood Together

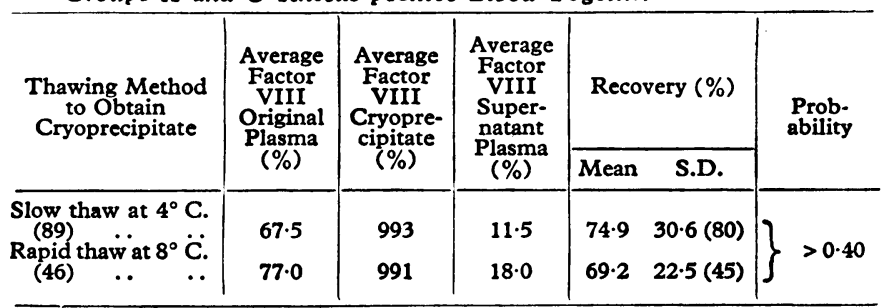

Sample sizes in parentheses.

S.D. = Standard deviation.

There is no statistically significant difference between the percentage recoveriea of factor VIII obtained by the two methods $(P>0.40)$.

Efficacy of Cryoprecipitate.-The results in patients treated with cryoprecipitate prepared by the slow and rapid methods of thawing are considered together, as no statistical difference was shown between them. The number of bags used per dose ranged from 2 to 10 . Each bag contained an average of $12 \mathrm{ml}$. of fluid, but volumes infused ranged from 23 to $116 \mathrm{ml}$., with an average of $70 \mathrm{ml}$. A total of 85 infusions were given during the trial period (537 bags). Table III shows the in-vivo response to cryoprecipitate prepared at both the hospital and the transfusion centre.

\begin{tabular}{|c|c|c|c|}
\hline & $\begin{array}{l}\text { Average Rise } \\
\text { Factor VIII } \\
\text { (\%) }\end{array}$ & $\begin{array}{c}\text { Recovery } \\
(\%)\end{array}$ & $\begin{array}{l}\text { Average } \\
\text { Dose } \\
\text { (units/kg.) }\end{array}$ \\
\hline 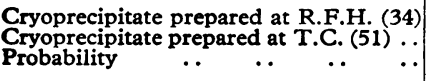 & $\begin{array}{l}18.5 \\
21.5 \\
<0.001\end{array}$ & $\begin{array}{l}69 \\
77 \\
<0.01\end{array}$ & $\begin{array}{l}12 \cdot 6 \\
12 \cdot 2 \\
>0 \cdot 4\end{array}$ \\
\hline
\end{tabular}

TABLE III.-In-vivo Response to Cryoprecipitate Prepared Both at the Royal Free Hospital (R.F.H.) and at the Transfusion Centre (T.C.) Shown as Average Factor VIII \% Rise, Percentage Recovery, and Dose in Units/kg.

Number of infusions analysed in parentheses.

Supernatant Plasma.-A total of 124 bags of supernatant frozen plasma was used during the trial period. The average content of factor IX (32 hags) was approximately $86 \%$ and that of factor XI (66 bags) $90 \%$. The material was used, at a dose of $15 \mathrm{ml} . / \mathrm{kg}$. body weight, in the successful treatment of several episodes of haematuria and one of acute abdomen, in three patients with factor IX deficiency. One patient with factor XI deficiency was treated for several episodes of haematuria and a gastrointestinal haemorrhage. The average in-vivo

\begin{tabular}{|c|c|c|c|c|}
\hline & & $\begin{array}{l}\text { Group O Positive } \\
\text { Average Factor } \\
\text { VIII }(\%)\end{array}$ & $\begin{array}{l}\text { Group A Positive } \\
\text { Average Factor } \\
\text { VIII }(\%)\end{array}$ & Probability \\
\hline \multirow{2}{*}{\multicolumn{2}{|c|}{$\begin{array}{l}\text { Frozen plasma in bottles.: } \\
\text { Fresh-frozen plasma in } \\
\text { bags }\end{array}$}} & $64 \cdot 0(52)$ & $66 \cdot 0(51)$ & $>0.50$ \\
\hline & & $72.0(380)$ & $84 \cdot 0(130)$ & $<0.001$ \\
\hline Probability & .. & $<0.05$ & $<0.001$ & \\
\hline
\end{tabular}
rise in factor IX was $14 \%$ and in factor XI $20 \%$.

TABLE IV.-Comparison of Factor VIII Content in Fresh-frozen Plasma in Bags and Frozen Plasma in Bottles in Group $O$ and $A$ Rhesuspositive Donors

Sample sizes in parentheses. 
Factor VIII Activity and Efficacy in Whole Plasma Preparations.- In both blood groups $\mathrm{A}$ and $\mathrm{O}$ rhesus-positive the factor VIII levels were significantly higher in the fresh-frozen plasma in plastic bags than in the frozen plasma in bottles (Table IV).

Table V.-In-vivo Response to Fresh-frozen Plasma in Bags and Frozen Plasma in Bottles Shown as an Average Factor VIII Rise and as a Percentage Recovery

\begin{tabular}{|c|c|c|c|c|}
\hline Factor VIII & & $\begin{array}{c}\text { Fresh-frozen } \\
\text { Plasma in Bags } \\
\text { A + O Positive }\end{array}$ & $\begin{array}{l}\text { Frozen Plasma } \\
\text { in Bottles } \\
\text { A + O Positive }\end{array}$ & Probability \\
\hline $\begin{array}{l}\text { Average rise }(\%) \ldots \\
\text { Recovery }(\%)\end{array}$ & $\begin{array}{l}\ldots \\
\cdots\end{array}$ & $\begin{array}{l}18 \cdot 5(46) \\
75 \cdot 0(46)\end{array}$ & $\begin{array}{r}9.0(48) \\
43.0(48)\end{array}$ & $\begin{array}{l}<0.001 \\
<0.001\end{array}$ \\
\hline
\end{tabular}

Number of infusions analysed in parentheses.

Though the average factor VIII level of the frozen plasma in bottles was $66 \%$, in more than half it was below $60 \%$. Table $\mathrm{V}$ shows the average rise per cent. and percentage recovery in patients. The in-vivo recovery of the fresh-frozen plasma prepared at the hospital in bags was $32 \%$ higher than that from the "Fresh Frozen Plasma" in bottles.

\section{Discussion}

The modern treatment of haemophilia and allied bleeding disorders depends on the adequate replacement of the deficient clotting factor. In assessing individual requirements several clinical criteria, such as the severity of the bleed, intended manipulative or operative procedures, and the length of treatment contemplated must be taken into account. Moreover, while improved therapeutic material now promises a brighter prognosis, the efficacy of any preparation must be regularly checked by the laboratory.

Cryoprecipitate has many advantages. The concentrated factor VIII can be given as a single quick injection. The danger of circulatory overload is minimized because of the small volume given. So far no patient receiving cryoprecipitate at this hospital has had any adverse reaction, despite the fact that neither Piriton (chlorpheniramine) nor hydrocortisone was given even to those patients who had needed these drugs to cover whole-plasma infusions.

The thawing of cryoprecipitate at $37^{\circ} \mathrm{C}$. is rapid, and the dose should be prepared and given within 30 minutes of taking the material from the deep freeze. Despite the advantages of cryoprecipitate, this product is still rather expensive, both in terms of the pints of blood required per dose (about twice the number necessary to prepare fresh-frozen plasma) and financially.

Of a total of 88 haemarthroses in patients suffering from haemophilia $76(86 \%)$ were treated on an outpatient basis (Table VI). In most cases single doses of therapeutic material proved sufficient to alleviate symptoms and allow early movement and mobilization of the affected joint. Treatment of the more severe haemarthroses of ten involved giving plasma replacement therapy not only at the onset of haemorrhage but to cover the early period of mobilization. Patients with more serious lesions-acute abdomen or cerebral haemorrhage, for example-and those undergoing dental extractions were given

\begin{tabular}{|c|c|c|c|c|c|c|}
\hline \multirow{3}{*}{ Lesion } & \multirow{2}{*}{\multicolumn{3}{|c|}{$\begin{array}{c}\begin{array}{c}\text { Fresh-frozen and Frozen } \\
\text { Plasma }\end{array} \\
\text { Episodes }\end{array}$}} & \multicolumn{3}{|c|}{ Cryoprecipitate } \\
\hline & & & & \multicolumn{3}{|c|}{ Episodes } \\
\hline & Total & $\begin{array}{c}\text { Out- } \\
\text { patient }\end{array}$ & $\begin{array}{c}\text { In- } \\
\text { patient }\end{array}$ & Total & $\begin{array}{c}\text { Out- } \\
\text { patient }\end{array}$ & $\begin{array}{c}\text { In- } \\
\text { patient }\end{array}$ \\
\hline $\begin{array}{lc}\text { Haemarthrosis } & \ldots \\
\text { Muscle bleeds } & \ldots \\
\text { Dental extraction } & \ldots \\
\text { Decidual dental bleeds } \\
\text { Others } \quad . . & . .\end{array}$ & $\begin{array}{r}60 \\
6 \\
5 \\
3 \\
5\end{array}$ & $\begin{array}{r}52 \\
4 \\
0 \\
2 \\
0\end{array}$ & $\begin{array}{l}8 \\
2 \\
5 \\
1 \\
5\end{array}$ & $\begin{array}{r}28 \\
6 \\
3 \\
1 \\
5\end{array}$ & $\begin{array}{r}24 \\
6 \\
0 \\
1 \\
0\end{array}$ & $\begin{array}{l}4 \\
0 \\
3 \\
0 \\
5\end{array}$ \\
\hline
\end{tabular}

cryoprecipitate in sufficient dosage to maintain levels of factor VIII of over $30 \%$ for the necessary length of time.

Since frozen plasma was first prepared in the 1920s (Feissly, 1925 ; Payne and Steen, 1929), increasing knowledge of the clotting mechanism has led to the development of more rapid procedures in order to preserve labile factors. The introduction of plastic bags has been another major advance. Walter (1950, 1952), Walter and Murphy (1952), and Walter et al. (1957) have referred to them as the ideal system. The higher cost per unit of blood in bags compared with blood in bottles is outweighed by the more effective use of blood and donors. In this hospital we have prepared 2,019 components, starting with 914 pints of blood.

There is no doubt that the therapeutic efficacy of fresh-frozen plasma prepared in plastic bags at the hospital haemophilia centre was much superior to the frozen plasma in bottles originally supplied. Many of these bottles were below the factor VIII level of $60 \%$-the lowest level from which an adequate therapeutic response could be expected (Preston, 1967) (see Chart). The time lag between the blood donation and preparation of the frozen plasma in bottles was probably the most important reason for this difference. The ease and rapidity of the plastic-bag method may help to preserve factor VIII activity. It is possible, moreover, that factor VIII is adversely affected by contact with glass (Anstall et al., 1961), though Preston (1967) could demonstrate no such effect.

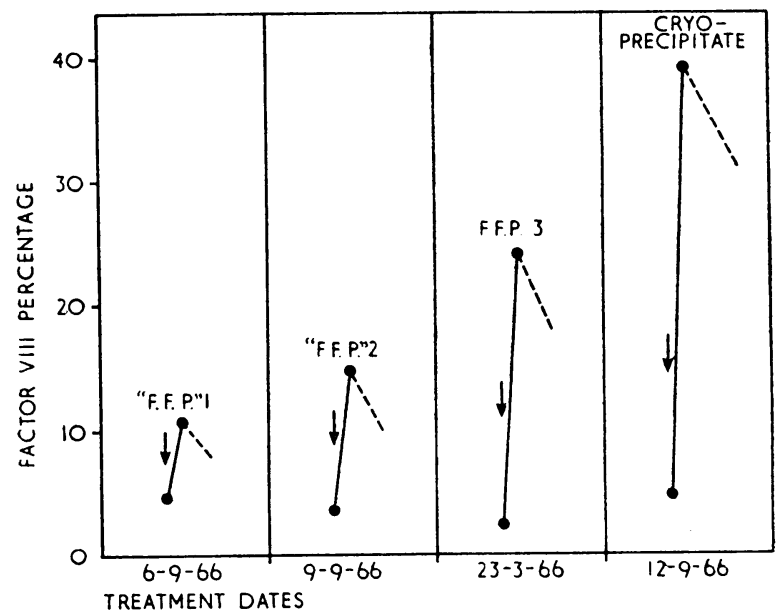

Results achieved with different plasma preparations in treating haemophilic boy aged 15 years, weight $59 \mathrm{~kg}$. "F.F.P." 1 and $2=$ "Fresh Frozen Plasma" issued in bottles by two separate regional blood transfusion centres for the treatment of haemophilia. $1,025 \mathrm{ml}$. given $(17 \mathrm{ml}$. $/ \mathrm{kg}$.). Factor VIII $1=49 \%$; $2=59 \%$. F.F.P. $3=$ fresh-frozen plasma prepared in plastic $2=59 \%$. F.F.P. $3=$ fresh-frozen plasma prepared $750 \mathrm{ml}$. given (13 ml. $/ \mathrm{kg}$.$) . Factor VIII =74 \%$. Cryoprecipitate $=100 \mathrm{ml}$. $(13 \mathrm{ml} . / \mathrm{kg}$.$) . Factor VIII =74 \%$. Cryoprecipitate
given (eight bags). Factor VIII $=1,200 \%$.

Hospitals in this area seem to prefer the reconstituted red cells which remain as a by-product after the preparation of cryoprecipitate, rather than the packed red cells which remain after the preparation of fresh-frozen plasma in plastic bags. For this reason cryoprecipitate is now prepared in bulk by the transfusion centre and issued for the routine treatment of all haemophilic haemorrhage. Since, from the clinical point of view, this has been entirely satisfactory, the possibility of changing over to plastic equipment, from glass bottles, throughout the area is now being considered. The higher cost of plastic bags, compared with that of bottles per pint of blood processed, can be offset only by $(a)$ the centralized, co-ordinated bulk buying of technically satisfactory plastic bags based on a review of competitive products ; $(b)$ the saving in staff; and (c) the more competent use of blood. This last circumstance can be achieved only by the continued education of clinicians, nurses, and technicians in the handling of plastic equipment and in the management of plasma component therapy. 


\section{Summary and Conclusions}

A trial to assess the best method of preparing suitable material for the routine infusion treatment of coagulation disorders is reported. The following conclusions have been reached:

1. Cryoprecipitate is an extremely valuable therapeutic material for the treatment of haemophilia, particularly where high levels of factor VIII need to be reached and maintained; in young patients; and for patients with incipient congestive cardiac failure. From many points of view it is the therapeutic material of choice.

2. Fresh-frozen plasma in plastic bags is effective provided that the factor VIII level to be attained need not be higher than $20-25 \%$, and provided that the volume to be infused can be tolerated. It has the added advantage that it can be used for the treatment of Christmas disease and other factor deficiencies as well as for haemophilia.

3. "Fresh Frozen Plasma" as supplied to some hospitals in glass bottles is often unsuitable for the treatment of haemophilia. It can be used for the treatment of patients with serum-factor deficiencies.

A change-over on a national scale from glass bottles to the closed plastic-bag system offers a solution to the problem of providing adequate therapeutic material for the treatment of haemophilia. Apart from providing material rich in factor VIII, the method also yields other useful blood components.

We acknowledge with thanks the preliminary work of $\mathrm{Dr}$ Charmian Goldwyn in establishing the bank of fresh-frozen plasma at the North-western Branch of the Royal Free Hospital ; the technical assistance of Miss M. I. Clatworthy; and the help of Dr. Anita $M$. Follows (Ali). We thank the medical students who have so willingly donated blood; also Baxter's Laboratories Ltd. for a free supply of plastic bags.

This report is based on a paper read at the meeting of the Association of Clinical Pathologists in London in September 1966.

\section{REFERENCES}

Anstall, H. B., Grove-Rasmussen, M., and Shaw, R. S. (1961). Transfusion, 1,87

Bennett E. and Dormandy, K. (1966). Lancet, 2, 731.

Biggs, R., and Macfarlane, R. G. (1962). Human Blood Coagulation and its Disorders, 3rd ed., p. 404 . Oxford. (1966). Treatment of Haemophilia and Other Coagulation Disorders, p. 350 . Oxford.

Brown, D. L., Hardisty, R. M., Kosoy, M. H., and Bracken, C. (1967). Brit. med. ₹., 2, 79

Dormandy, K. M., Gandy, R. R., Follows (Ali), A. M., and Britten, M. I. (1967). Communication given to the 10th World Congress of the International Society for the Rehabilitation of the Disabled, WiesInternational Society for the Reh.

beissly, R. (1925). $7 b$. Kinderheilk., 110, 297.

Feissly, R. (1925). Fb. Kinderheilk., 110, 297. haemorrh. (Stuttg.), 7, 215 .

Kliman, A., and Schwab, P. J. (1961). Amer. F. clin. Path., 36, 379.

Payne, W. W., and Steen, R. E. (1929). Brit. med. F., 1, 1150 .

Pool, J. G., and Shannon, A. E. (1965). New Engl. f. Med., 273, 1443. Preston, A. E. (1967). Brit. F. Haemat., 13, 42.

Simson, L. R., Oberman, H. A., Penner, J. A., Lien, D. M., and Warner, C. L. (1966). Amer. Ұ. clin. Path., 45, 373.

Walter, C. W. (1950). Surg. Forum, 1, 483.

Walter, C. W. (1950). Surg. Forum, 1, 129. Button, L. N., and Ritts, R. Е. (1957). Surg. Gynec. Obstet., 105, 365 . and Murphy, W. P. (1952). Ibid., 94, 687.

\title{
Controlled Trial of Demigran in the Prophylaxis of Migraine
}

\author{
P. HUDGSON,* M.B., M.R.A.C.P. ; J. B. FOSTER, $\dagger$ M.B., M.R.C.P. ; D. J. NEWELL, $\ddagger$ M.A., PH.D.
}

Brit. med. F., 1967, 2, 91-93

Effective preventive treatment of migraine remained a hope rather than a reality for many years until the introduction of the lysergic acid derivative, methysergide, in 1959. Subsequent studies, including a double-blind cross-over trial (Southwell et al., 1964), have shown that it is an effective prophylactic in about $70 \%$ of all cases of recurrent severe migraine. However, attention has also been directed towards the possible application of corticosteroid hormones in the prophylaxis of migraine because of the well-known variations in the severity of the disease with menstruation, pregnancy, and, of late, the use of oral contraceptives (Mears and Grant, 1962; Whitty et al., 1966). Trials have been carried out with androgens (Blumenthal and Fuchs, 1951 ; Jönsson et al., 1951 ; Keil, 1953 ; Moehlig, 1955 ; Roberts, 1955 ; Als and Jacobsen, 1964) and parenteral progesterone (Singh et al., 1947 ; Blumenthal and Fuchs, 1951 ; Steinkamm, 1951 ; Adlercreutz, 1953 ; Keil, 1953 ; Schneider, 1955). However, both methods of treatment have serious disadvantages, androgens because of their virilizing effect and progesterone because of the inconvenience of giving injections over a long period of time. Interest has therefore centred on the development of oral progestational agents, and several of these have been shown to have at least some effect in preventing recurrent attacks of migraine (Lundberg, 1962, 1963).

Lundberg (1965) claimed that a modified oral progestogen, $6 \alpha$-trifluoromethyl-17 $\alpha$-acetoxyprogesterone (W.G.537, Demigran) is particularly effective in this respect. This drug was prepared by Godtfredsen and Vangedal (1961), and was claimed to have no progestational or metabolic effects in the human (Sørensen, 1964), though Lundberg (1965) reported minor dis- turbances of menstrual rhythm in 12 out of 32 women taking the drug in doses between 10 and $20 \mathrm{mg}$. daily. It was therefore decided to subject the drug to a crossover trial, the results of which are reported in this paper. After consideration we decided to use methysergide rather than placebo as the control. This was done for two reasons ; firstly, because of its established efficacy as a prophylactic in migraine, and, secondly, because we felt that it was unreasonable to ask patients with frequent severe attacks to submit to placebo treatment for long periods. This was, we felt, particularly important in those patients in whom partial or complete prophylaxis had already been effected by some form of interval treatment. In this context it should be noted that, in spite of the obvious disadvantage of using tablets of different appearances, the code was not broken by any of the patients who completed the trial.

\section{Patients}

Fifty-three patients were included in the trial. All had frequent severe attacks of typical migraine, and had required interval treatment at some time in the past. Most of them were under 40 , but a few of middle age were included who had frequent disabling attacks. The average number of headaches

\footnotetext{
* Senior Registrar in Neurology.

† Consultant Neurologist.

₹ Reader in Biostatistics.

Regional Neurological Centre, Newcastle General Hospital, and the
Nuffield Department of Industrial Health, University of Newcastle upon Tyne.
} 